\title{
PERANCANGAN SISTEM KAMAR KOS PINTAR BERBASIS IoT
}

\author{
Ricky Novian Riyadi ${ }^{1}$, Esti Wijayanti ${ }^{2}$, Alif Catur Murti ${ }^{3}$ \\ ${ }^{1,2,3}$ Program Studi Teknik Informatika, Fakultas Teknik, Universitas Muria Kudus \\ Email: ${ }^{1} 201651152 @$ std.umk.ac.id, ${ }^{2}$ esti.wijayanti@umk.ac.id, ${ }^{3}$ alif.catur@umk.ac.id
}

(Naskah masuk: 7 Desember 2020, diterima untuk diterbitkan: 30 Desember 2020)

\begin{abstract}
Abstrak
Memaksimalkan penggunaan teknolgi seperti sekarang ini adalah merupakan sebuah langkah kreatif, terlebih lagi pada saat pandemic seperti ini. Meminimalisir pengeluaran menjadi tujuan utama, pengeluaran yang bersifat rutin seperti penggunaan listrik, air , dan gas sebisa mungkin bisa ditekan. Hal semacam ini dialami oleh para perantau pekerja/mahasiswa yang memilih tinggal di sebuah kos. Terkadang kelalaian yang menjadikan pengeluaran dalam satu bulan menjadi boros, kelalaian yang sifatnya sederhana seperti lupa mematikan peralatan elektronik ketika meninggalkan kos. Desain kamar kos pintar berbasis IoT menjadi sebuah solusi yang inovatif dengan memanfaatkan teknologi internet, device android, aplikasi BOT telegram, Wemos dan penggunaan microcontroller. Desain penggunaan yang mudah menjadi keunggulan dalam perancangan kamar kos pintar ini. Pengguna tinggal memberikan perintah untuk mematikan/menghidupkan berbasis text melalui telegram dan secara otomatis akan menjalankan perintah tersebut. Desain ini dapat berjalan secara optimal dalam upaya untuk meminimalisir pemborosan biaya, khususnya dalam pembayaran tagihan listrik.
\end{abstract}

Kata kunci: Kamar kos pintar, IoT, Android, Mikrokontroler

\section{DESIGN OF IOT-BASED SMART BOARDING ROOM SYSTEM}

\begin{abstract}
Maximizing the use of technology as it is today is a creative step, especially during a pandemic like this. Minimizing expenditures is the main goal, routine expenditures such as the use of electricity, water, and gas as much as possible can be reduced. This kind of thing is experienced by workers / students who choose to live in a boarding house. Sometimes omissions that make spending in one month extravagant, simple omissions such as forgetting to turn off electronic equipment when leaving the cost. IoT-based smart boarding room design becomes an innovative solution by utilizing internet technology, android devices, telegram BOT application, Wemos and the use of microcontrollers. Easy-to-use design is an advantage in the design of this smart boarding room. Users just give a command to turn off / turn on text-based via telegram and will automatically execute the command. This design can run optimally in an effort to minimize waste of costs, especially in the payment of electricity bills..
\end{abstract}

Keywords: Smart boarding room, IoT, Android, Microcontroller

\section{PENDAHULUAN}

Memaksimalkan penggunaan teknolgi seperti sekarang ini adalah merupakan sebuah langkah kreatif, terlebih lagi pada saat pandemic seperti ini. Meminimalisir pengeluaran menjadi tujuan utama, pengeluaran yang bersifat rutin seperti penggunaan listrik, air , dan gas sebisa mungkin bisa ditekan. Hal semacam ini dialami oleh para perantau pekerja/mahasiswa yang memilih tinggal di sebuah kos. Merebaknya permasalahan ekonomi sosial yang terjadi dimasyarakat luas.

Banyak masalah yang sering terjadi di tengah masyarakat terutama di perkotaan, tidak bisa dihindari lagi bahwa era perkembangan teknologi zaman di saat ini, pastilah menimbulkan beberapa masalah di tengah masyarakat luas, terutama dalam mengontrol peralatan listrik. Terkadang kelalaian yang menjadikan pengeluaran dalam satu bulan menjadi boros, kelalaian yang sifatnya sederhana seperti lupa mematikan peralatan elektronik ketika meninggalkan kos.

Era teknologi sekarang ini membuat manusia berfikir inovatif, tidak hanya mencari hal - hal baru, akan tetapi juga memaksimalkan hasil dari teknologi yang sudah ada untuk membantu pekerjaan manusia sehari - hari,

Perkembangan teknolog yang didukung dengan akses internet yang cepat dan beberapa kemudahan dalam konektifitas memunculkan berbagai macam 
ide pengembangan dalam memaksimalkannya. IoT menjadi trend pada saat ini karena dalam prakteknya jarak menjadi tidak berarti ketika ada internet yang terhubung ke sebuah device (Krisna Affandi, 2019).

Berdasarkan kondisi tersebut perlu dirancang sebuah kamar kos pintar berbasis IoT untuk menekan pengeluaran dalam hal penghematan konsumsi daya listrik.

\section{LANDASAN TEORI}

\subsection{Sistem}

Sistem adalah adalah bagian dari elemenelemen yang berkumpul dan berinteraksi untuk menyelesaikan masalah untuk mencapai tujuan. Dimana dapat digambarkan sebagai data, program, maupun algoritma, Sistem dibangun untuk meunjukkan efektifitas dan efisien sebuah komponen yang saling terintegrasi (Jogiyanto, 2005), (Prahasta, 2005).

\subsection{Kamar kos}

Rumah kos atau sering juga disebut dengan koskosan merupakan salah satu kebutuhan bagi para mahasiswa yang sedang menempuh ilmu di daerah lain dari luar kampung halaman, dan rumah kos merupakan kebutuhan utama. Pada umumnya mahasiswa yang memiliki prekonomian tinggi akan tinggal di sebuah apartemen atau guest house atau hotel, namun bagi mahasiswa yang memiliki kondisi ekonomi menengah kebawah, biasanya akan tinggal di sebuh kamar tinggal yang biasanya di sebut dengan rumah kos, atau sering juga di sebut dengan kos-kosan (Rosadi dan Andriawan, 2016)

\subsection{Internet of Things (IoT)}

IoT adalah pola dasar yang bertujuan untuk memberikan gagasan baru di bdang teknologi informasi dan komunikasi, dalam model IoT "Segalanya" dapat terhubung dengan internet, sehingga informasi dapat diolah dan disebarkan dengan cepat. Oleh karena itu IoT sangat berperan penting dalam pengembangan smart city. (Misbahuddin, 2015)

\section{TINJAUAN PUSTAKA}

Ada beberapa penelitian sebelumnya yang melandasi peulis untuk meneliti terkait dengan desain kamar kos pintar berbasis IoT, penelitian tersebut diantaranya adalah Rancang Bangun Smart Home menggunakan Wemos D1 R2 Arduino Compatible Berbasis ESP8266 ESP-12F. (Kusuma, 2018), yaitu pengembangan mikrokontroler yang menggunakan internet sebagai media aksesnya dapat mengontrol peralatan rumah baik lampu led dari jarak jauh menggunakan wifi.

Penelitian Perancangan Prototype Sistem Kendali Lampu Menggunakan Handphone Android Berbasis Arduino. (Ahmad Fatoni, Dwi Bayu Rendra, 2014), yaitu pengembangan pengendalian lampu dari jarak jauh menggunakan arduino dan dengan media ponsel android.
Penelitian Aplikasi Bot Telegram Untuk Media Informasi Perkuliahan Program Studi Informatika-Sistem Informasi Bisnis Universitas Kristen Petra. (Loren N.G, Justinus A, Andres H, 2018), yaitu pemanfaatan bot telegram untuk media informasi perkuliahan yang dapat dilihat maupun aktivitas - aktivitas apa saja yang telah dilakukan oleh website dosen dan tata usaha.

Penelitian Rancang Bangun Smart Garden Berbasis Internet of Things (IoT) dengan Bot Telegram. (Krisna Affandi, 2019), yaitu pemanfaatan Internet of Things dan juga telegram yaitu bot chat untuk menerapkan kebun pintar yang dapat menyiram tanaman jarak jauh dan juga automasi menggunakan NodeMCU.

\section{HASIL DAN PEMBAHASAN}

\subsection{Perancangan Perangkat Keras/Hardware}

Penelitian ini menggunakan mikrokontroler Wemos D1 mini ESP8266 sebagai chip utama, merancang model sistem kamar kos yang dapat dikendalikan dan kemudian Sistem menyalakan dan mematikan lampu dan juga kipas pada model sistem kamar kos terkendali yang diusulkan. Dari sistem terdiri dari Wemos D1 Mini sebagai pusat kendali, yang dapat menyalakan lampu led, dan juga kipas angin dc 5v, pada gambar 1. Meruapakan blok diagram kamar kos pintar berbasis IoT.

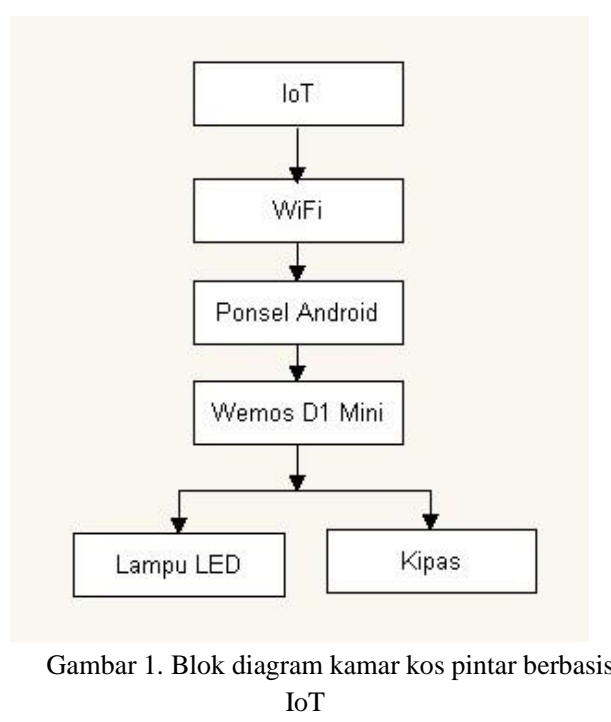
berikut :

Dari gambar 1, dapat dideskripsikan sebagai

- IOT (Internet of Things) berfungsi mengirim data ke chat bot Telegram dan mikrokontroler membaca data yang dikirim ke chat bot Telegram tersebut

- Wifi yang berfungsi sebagai media komunikasi antara mikrokontroler dengan koneksi hotspot internet.

- Ponsel android sebagai alat media untuk mengirimkan perintah dan menjadi 
penglaksana terjalannya program yang sudah dibuat.

- Wemos D1 Mini berfungsi sebagai pusat kendali dari sistem kerja rangkaian yang digunakan untuk mengontrol rangkaian secara keseluruhan mulai dari input sampai dengan semua output yang digunakan dalam perancangan alat pengendali peralatan listrik di kamar kos berbasis internet of things menggunakan mikrokontroler

Setelah blok diagram terbentuk maka perlu adanya perancangan perangkat keras dan konfigurasinya. Berikut ini adalah merupakan perancangan perangkar keras dan konfigurasinya :

- Mikrokontroler Wemos D1 mini merupakan mikrokontroler yang didalamnya terdapat sebuah chip yang programmable. Adapun komponen mekanik, elektroni dan power yang ditempatkan pada rangka dengan penempatan yang sesuai dengan ruang tempat yang diperlukan memiliki panjang $34,2 \mathrm{~mm}$ x 25,6 $\mathrm{mm}$

Pada perancangan hardware pinout yang terdapat pada Wemos D1 Mini, penulis menggunakan GPIO16, GPIO14, GPIO12 dan GND. Berikut penjelasannya :

- GPIO16 yaitu D0 digunakan untuk mengontrol hidup dan matinya lampu1

- GPIO14 yaitu D5 digunakan untuk mengontrol hidup dan matinya lampu2

- GPIO12 yaitu D6 digunakan untuk mengontrol hidup dan matinya kipas

Antar muka perancangan adalah seperti pada gambar 2.

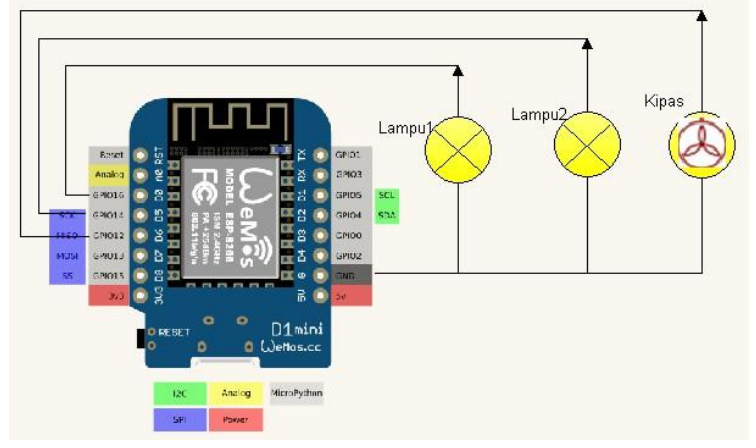

Gambar 2. Antarmuka perancangan

Berdasarkan gambar diatas, penulis akan menghubungkan Lampu 1 ke D0, Lampu 2 ke D5, lalu Kipas ke D6. Jika pengguna mengirimkan perintah untuk menyalakan lampu atau kipas maka mikrokontroler akan memberikan logika "1" yaitu ON pada pin yang diberikan ke masing - masing lampu atau kipas, jika pengguna mengirim perintah untuk mematikan maka mikrokontroler akan memberikan logika "0” yaitu OFF.

Pada gambar 3 adalah merupakan gambar diagram kamar kos pintar berbasis IoT.

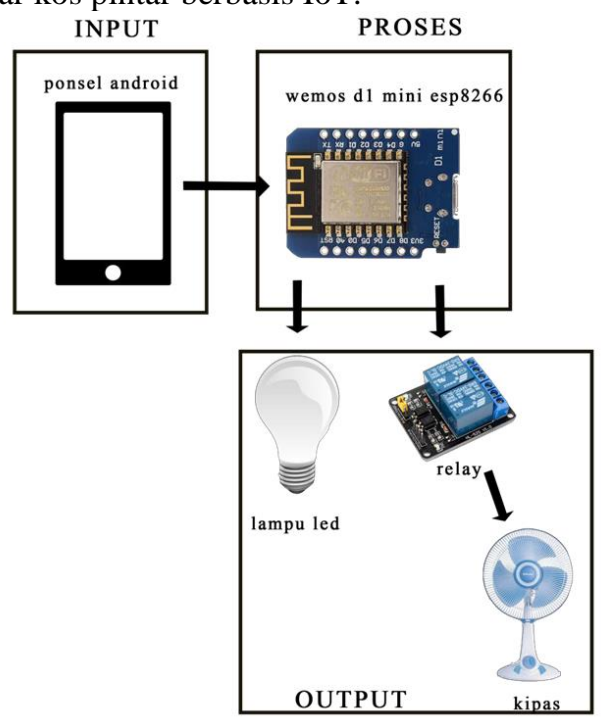

Gambar 3. Diagram kamar kos pintar berbasis IoT

Perangkat ini terdiri dari ponsel android, wemos D1 mini yang telah ada modul Wi-Fi yaitu ESP8266. Sistem ini mendeteksi perintah yang dikirimkan pengguna melalui ponsel android. Apabila mikrokontroler Wemos D1 Mini membaca adanya perintah pada lampu, dan juga kipas angin. Maka sistem yang ada pada Wemos akan secara otomatis memenuhi perintah dari pengguna yang pengguna telah programkan pada Wemos tersebut. Untuk pengontrolan sistem dibantu router sebagai sarana komunikasi sistem kepada jaringan internet. Pengguna dapat mengontrol kondisi rumah yang telah dibuat melalui aplikasi telegram pada perangkat Wemos.

\subsection{Perancangan Perangkat Lunak/Software}

Dalam perancangan perangkat lunak, bahasa yang digunakan dalam perancangan lunak adalah bahasa $\mathrm{C} / \mathrm{C}++$ dengan beberapa library tambahan untuk perancangan sistem kamar kos terkendali berbasis wemos ini seperti library arduinojson, universalarduinotelegrambot menggunakan arduino IDE. Untuk memperjelas, berikut ditampulkan flowchart pada gambar 4 yang menjelaskan perancangan sistem secara umum bagaimana diagram alir program utama dari desain sistem kamar kos pintar pada penelitian ini : 
20 Indonesia Journal of Technology, Informatic and Science (IJTIS), Vol. 2, No. 1, Desember 2020, hlm. 17-21

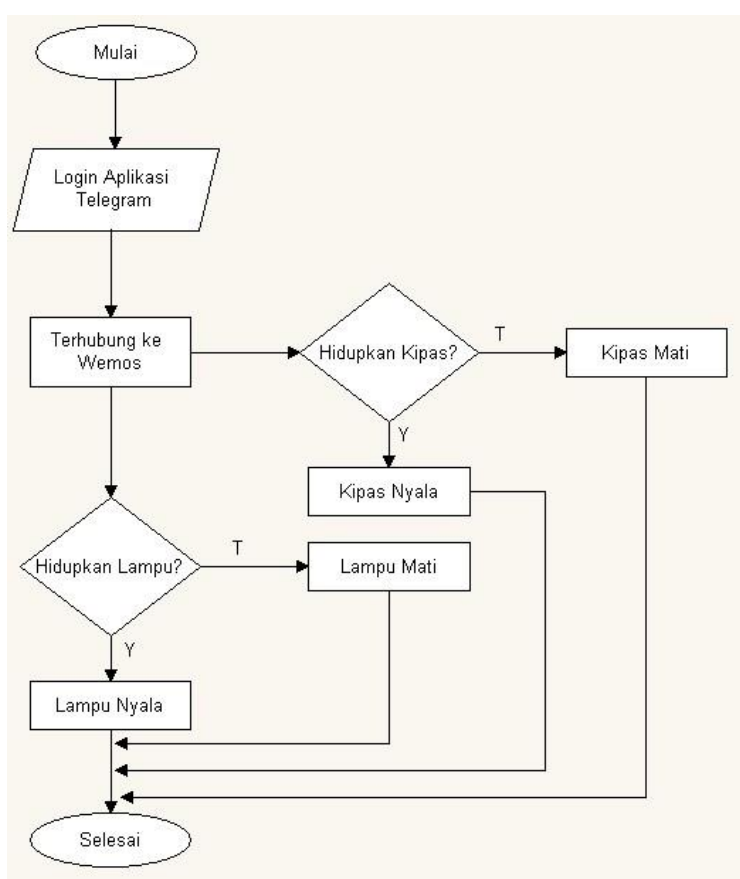

Gambar 4. Flowchart kamar kos pintar berbasis IoT

\subsection{Implementasi}

Pada tahap implementasi kita dapat melihat kesesuaian anatara perancangan dengan hasil dari yang dibuat. Pada gambar 5 merupakan hasil dari coding setelah diupload.

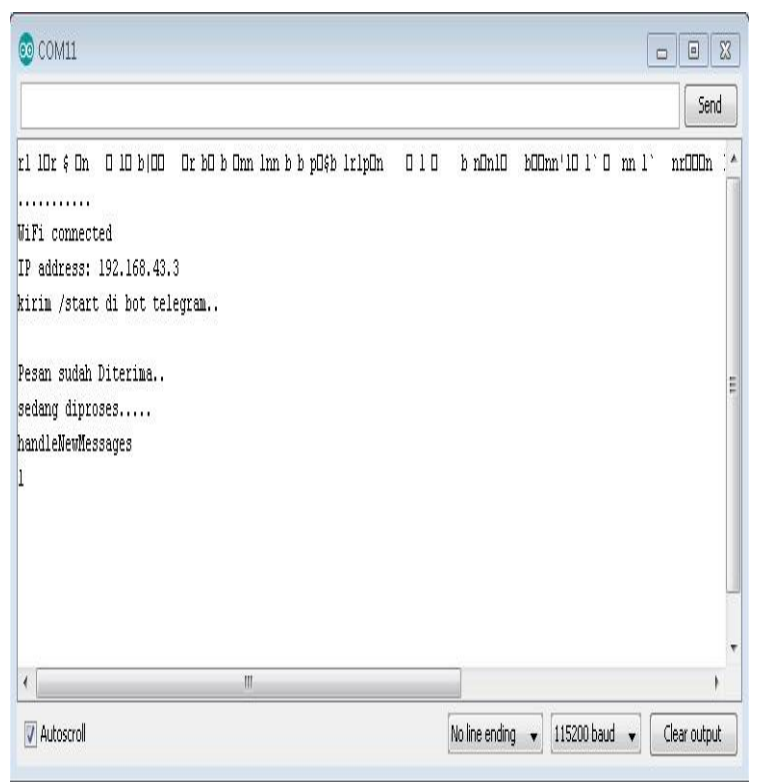

Gambar 5. Serial Port Setelah Upload Coding

Hasil impelementasi dari sistem yaitu setelah koding wemos mikrokontroler akan terkoneksi ke jaringan nirkabel yang telah kita konfigurasikan di mikrokontroler tersebut dan mendapatkan ip address tersebut.

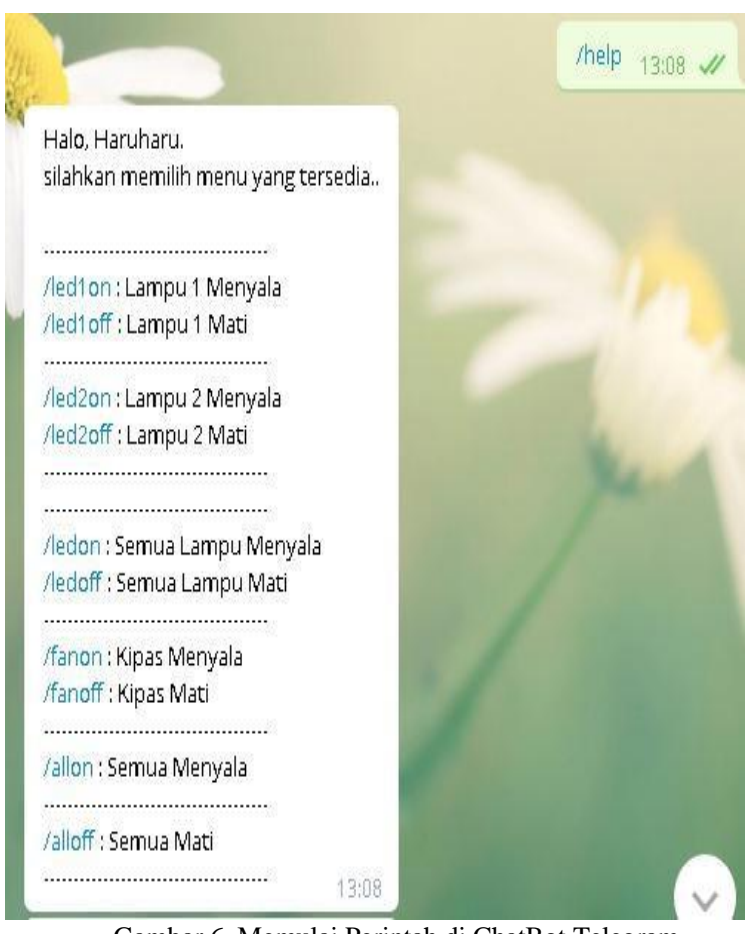

Gambar 6. Memulai Perintah di ChatBot Telegram

Pada gambar 6, jika kita mengirim perintah ke bot chat di Telegram dengan perintah /start maka mikrokontroler akan mengirimkan pesan berupa text. Saat kita mencoba mengirimkan perintah untuk menyalakan sebagian lampu satu atau dua sebagai pada gambar 7 , dan pada gambar 8 merupakan keadaan prototype ketika perintah dijalankan, seperti berikut:

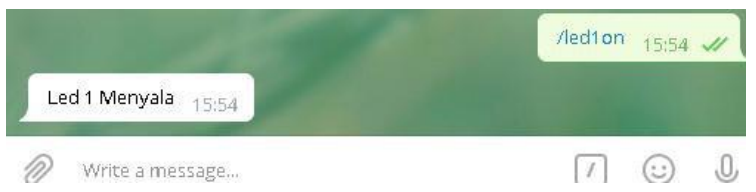

Gambar 7. Mengirimkan Perintah di ChatBot Telegram

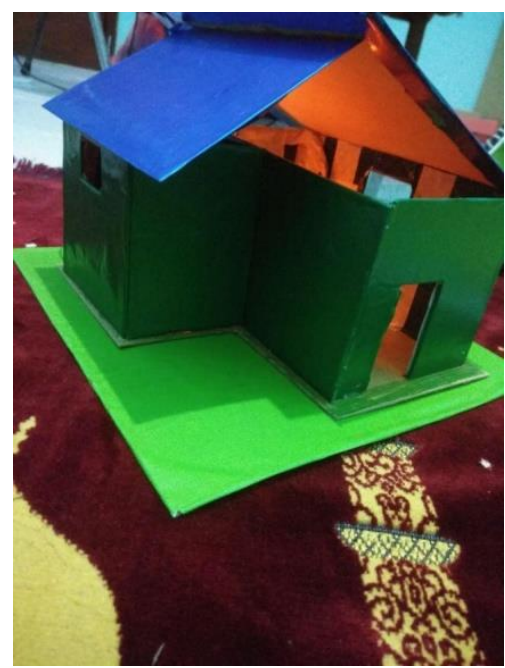

Gambar 8. Prototype kamar kos pintar berbasis IoT 


\section{KESIMPULAN}

Melihat hasil dari pembahasan dan analisa dari perancangan yang sudah dibuat maka dapat disimpulkan bahawa :

1. Pengujian sistem alat secara keseluruhan menunjukkan bahwa alat dapat menjalankan perintah yaitu menyalakan dan mematikan perangkat elektronik.

2. Pengujian terhadap perangkat - perangkat inputan yaitu pengujian koneksi Wemos D1 Mini ke Aplikasi Telegram.

3. Alat yang dirancang dan dibuat dengan menggunakan mikrokontroler board Wemos D1 Mini sebagai perangkat utama dari penelitian tersebut dan dilengkapi dengan beberapa perangkat seperti relay, lampu LED 2 buah, kipas DC 5v.

4. Alat ini memiliki spesifikasi program yang sudah cukup baik dalam menjalankan perintah - perintah yang telah di program, sehingga dapat menjalankan perintah dengan baik.

\section{DAFTAR PUSTAKA}

Affandi, K., 2019, Rancang Bangun Smart Garden Berbasis Internet Of Thing (IoT) dengan Bot Telegram, Seminar Nasional Teknologi Informasi dan Komunikasi 2019 Hal 165169

Fatoni, A.,Rendra, D, B., 2014, Perancangan Prototype Sistem Kendali Lampu Menggunakan Handphone Android Berbasis Arduino, Jurnal PROSISKO Vol. 1 Hal 23-29

Gunawan, L, N., Anjarwirawan, J., Handojo, A., 2018, Aplikasi Bot Telegram Untuk Media Informasi Perkuliahan Program Studi Informatika-Sistem Informasi Bisnis Universitas Kristen Petra, JURNAL INFRA Vol 6 No 1

Jogiyanto, 2005, Analisis dan Disain Sistem Informasi, Andi Offset, Yogyakarta.

Kusuma, N, A, A.,Yuniarti, E., Aziz, A., 2018, Rancang Bangun Smarthome Menggunakan Wemos D1 R2 Arduino Compatible Berbasis ESP8266 ESP-12F, AL-FIZIYA VoL I. No. 1

Misbahuddin, S., Zubairi, J, A., Saggaf, A., Basuni, J., A-Wadany, S., Al-Sofi, A., 2015, IoT based dynamic road traffic management for smart cities, 12th International Conference on High-capacity Optical Networks and Enabling/Emerging Technologies (HONET) 142-146

Prahasta, Eddy., 2006, Sistem Informasi Geografis: Tutorial Arcview, Informatika,

Rosadim D., Andriawan, F,O., 2016, Aplikasi Sistem Informasi Pencarian Tempat Kos
Dikota Bandung Berbasis Android, Jurnal Computech \& Bisnis. Edisi 10, No. 1. hal. 50 